\title{
Standing in a Crowded Room: Exploring the Relation between Interest Group System Density and Access to Policymakers
}

Hanegraaff, Marcel; Van Der Ploeg, Jens; Berkhout, Joost

\section{Published in:}

Political Research Quarterly

DOI:

$10.1177 / 1065912919865938$

Publication date:

2020

Document version

Publisher's PDF, also known as Version of record

Document license:

CC BY-NC

Citation for published version (APA):

Hanegraaff, M., Van Der Ploeg, J., \& Berkhout, J. (2020). Standing in a Crowded Room: Exploring the Relation between Interest Group System Density and Access to Policymakers. Political Research Quarterly, 73(1), 51-64. https://doi.org/10.1177/1065912919865938 


\title{
Standing in a Crowded Room: Exploring the Relation between Interest Group System Density and Access to Policymakers
}

Political Research Quarterly

2020, Vol. 73(I) 5I-64

(C) 2019 University of Utah

(c) (i) (5)

Article reuse guidelines: sagepub.com/journals-permission DOI: 10.1 |77/10659/29/9865938 journals.sagepub.com/home/prq

(S)AGE

\section{Marcel Hanegraaff', Jens van der Ploeg ${ }^{2}$, and Joost Berkhout'}

\begin{abstract}
The numerous presence of interest groups may be a recipe for policy deadlock or, more optimistically, indicate the vibrancy of a political community. Population-ecology theory suggests that the number of interest groups active in a policy domain is relevant for strategies and political outcomes, such as policy access, and interest group density is expected to reduce access for individual organizations. Competitive pressures in dense domains necessitate groups to specialize to gain access to the policy access. We empirically assess this argument and indeed find lower levels of access in denser policy fields, moderated by specialization of organizations in lobbying. Furthermore, we identify important differences between mature (the Netherlands and Belgium) and young (Slovenia and Lithuania) interest group systems. These findings address theoretical concerns about the lack of linkages between micro- and macrostudies on interest representation.
\end{abstract}

\section{Keywords}

interest groups, civil society and voluntary groups, comparative politics, European politics, lobbying

\section{Introduction}

The political science subfield of the study of interest groups is split between macro- and micro-level studies. On one hand, the most prominent of the macro-level theories is the population ecology theory, initiated by Gray and Lowery (1996), which is currently applied broadly in the discipline of political science. Studies in this field explain the shape of interest group populations in terms of their density and diversity. These aggregate numbers have macro-level implications related to representation (e.g., related to representational biases), policy making (e.g., as cause of policy deadlock), or social stability (e.g., as a source of social cohesion). Micro-level studies, on the other hand, aim to explain variations in the strategies and influence of individual interest groups. Such behaviors and outcomes are predominantly explained on the basis of indicators such as resources spent on lobbying, the types of interests represented, and issue and venue characteristics (e.g., Bouwen 2004). Both theoretical foci have added much to the discipline and jointly form a relevant research community, but unfortunately hardly maintain effective conceptual linkages to each other (Halpin and Jordan 2012; Holyoke 2017; Lowery 2015).

This overall lack of linkages between the two types of studies is problematic for at least two reasons. First, to validate the importance of their work, scholars in the population ecology field routinely assume that the structure of interest group communities substantially affects "the use of influence tools" by interest groups (Lowery and Gray 2004, 167) and "access to the policymaking process" (Lowery and Gray 2015, 6). Yet, there are hardly any empirical examinations of these assumptions. This means that it remains unclear what the actual added value of the population ecology theory is for the broader political science literature. Second, the absence of a link between macro- and micro-level studies is a problem for the latter type of studies as well, as they potentially suffer from omitted variable bias or have external validity problems. That is, particular micro-level lobby behaviors are likely to be better explained when accounting for particular macro-level contextual factors such as the number of similar groups in a particular policy domain or system. Population-related factors also affect the external validity

\footnotetext{
'University of Amsterdam, The Netherlands
}

${ }^{2}$ University of Copenhagen, Denmark

\section{Corresponding Author:}

Joost Berkhout, Department of Political Science, University of Amsterdam, Nieuwe Achtergracht 166, 1012 DL Amsterdam, The Netherlands.

Email: d.j.berkhout@uva.nl 
of single-domain or single-system research designs. We therefore concur with Holyoke (2017, also see Holyoke 2015) when he notes that “the bifurcation of today's interest group literature between these two levels of analysis is a serious concern for theory development, research design, statistical modeling, and general progress in the subfield" (see also Baumgartner and Shoub 2015, 221; Leech 2015, 197; Lowery, Halpin, and Gray 2015, 267).

In this paper, we therefore aim to make a start in addressing this concern by innovatively analyzing whether the density of interest group systems affects the access groups have to political actors. In addition, we analyze whether population ecology theory provides us the necessary tools to explain which types of organizations persevere in dense communities (e.g., more specialized groups) and which are more likely to be excluded from the political process (e.g., encompassing groups). Empirically, we rely on a novel data set of more than three thousand organizations to test our assertions. This data set consists of various similar survey projects across different countries (namely, Belgium, the Netherlands, Slovenia, and Lithuania). In each of these countries, we have data on the structure of the interest group systems per policy domain and the access individual interest groups have to the policy process. Combined, this allows us to test whether macro-level population characteristics affect individual political outcomes, and whether these mechanisms follow the logic of population ecology theory.

In what follows, we first describe how macro-level studies of interest group communities are linked to studies of individual interest group behavior. Second, we provide hypotheses related to density and access gained, all derived from the organizational ecology literature. We then describe our data collection strategy and test our hypotheses. We end with a reflection on the findings and provide suggestions for additional research.

\section{The Link between Macro- and Micro- level Studies of Interest Groups}

For over a century, social and political scientists have theorized about the size of interest group populations and its consequences for political stability, economic welfare, and "unbiased" political decision making. Truman (1951) already noted over sixty years ago that the number of interest groups has a direct effect on the stability of political systems, as they provide the necessary checks and balances to political authorities. Truman was not alone in linking interest group density to political stability and moderation. We read similar arguments by Baumgartner and Leech $(1998,48)$ : "in the immediate postwar years, one of the explanations of America's success in maintaining democracy while other countries fell to fascism was the vibrant group system based on competition and independence from the state." Schattschneider (1960) and Olson (1982), by contrast, worried about the unintended effects of the indeterminate growth of interest group activity. They warned that control over public policy by narrow-interest, self-serving groups, increases with the number of groups present, and, according to Olson, such control will limit economic growth and ultimately lead to a decline of social and economic welfare.

Despite widespread attention, however, it was not until the late 1980s that researchers started to systematically analyze interest group systems as organizational populations. Gray and Lowery's work stands out in this regard. Their study on the populations of interest groups in the states of the United States has become a distinct subfield within the interest group literature. Especially innovative was the application of theories derived from biology, most prominently population ecology theory, to explain how interest group systems evolve over time and to explain their density and diversity at particular moments in time. Their work has been highly influential to many scholars studying interest group populations in the decades following their 1996 book (for overviews, see Hojnacki et al. 2012; Lowery and Gray 2015).

While its impact on the literature on interest group populations can hardly be overstated, the research did not fully live up to its initial promise. In Gray and Lowery's early work, they identified great potential for the population ecology theory to "provide us new opportunities to theoretically link micro- and institutional-level analyses of interest groups" (Lowery and Gray 1995, 25). More specifically, they stated, "the most important opportunities for future research may entail examining ... implications of our population level findings for the survival, influence strategies, and life histories of individual organizations" (Gray and Lowery 1996, 249-50). Yet, in recent work, Lowery and Gray $(2015,7)$ themselves have admitted that the latter objectives have not really been achieved and are still "an area of organizational ecology we have only begun to explore." Holyoke (2015) regards this lack of integration as a serious concern for theory development, research design, statistical modeling, and general progress in the subfield. Loomis (2015) has been even more outspoken and has questioned whether the links between this macro-level work and micro-level research are currently so fuzzy that the former might not contribute much to the interest group literature at all.

We are not as skeptical as Holyoke, and especially Loomis, as there certainly have been some (successful) attempts to link macro- and micro-level analysis. Yet, most were on linking population dynamics to mobilization patterns and organizational maintenance prospects (see, for instance, Gray and Lowery 1997a; Halpin and Jordan 2009). In addition, some studies have focused on 
the link between system density and the strategic choices groups make. For instance, Lowery et al. (2012) have found that in dense business interest communities, encompassing business groups are competitively excluded from the policy process by more specialized groups. Furthermore, the density of state interest group systems seems to affect the sponsoring of political action committees (PACs) in the United States (Gray and Lowery 1997b). More recently, Holyoke (2017) has found that merely taking into account the natural grouping of data by higher levels in the analysis, whether by interest niches, states, or levels of governance in the federal system, changed results significantly. The findings of Holyoke's study stress the importance of exploring which relevant relationships exist between population and interest group-level characteristics.

However, while studies on the link between interest group density and mobilization/strategic choices are already scarce, they are entirely absent when it comes to the link between population-level characteristics and political outcomes. For political outcomes, we have the blunt and commonly implicit assumption that larger numbers of groups almost inevitably lead to individual interest representatives having less access to the policy process, but to a higher aggregate potential influence by groups (e.g., Olson 1982; see discussion in Lowery 2015, 215; Schattschneider 1960). However, none of the studies in this tradition analyzes whether the density of interest group communities actually affects the access individual groups gain to policymakers, let alone whether this pattern follows the premises of population ecology theory. As a result, the contribution of population-ecological studies to the broader political science discipline, and the interest group literature more specifically, cannot be specified sufficiently.

\section{How Does Interest Community Density Affect Interest Group Access?}

To begin filling our knowledge gap on the drivers of policy access, we formulate a number of expectations derived from population ecology on how interest community density and policy access are related to each other. We focus, first, on the relation between the aggregate density in interest group communities and the access interest groups gain to policymakers. Second, we provide hypotheses about which types of organizations are more likely to gain access in a dense environment.

Our first aim is to explore the link between the density of interest group communities and the access opportunities interest groups have to policymakers. The relationship between crowdedness (density) of particular domains and access can best be understood by combining exchange theory and population ecology. Exchange-theoretical perspectives identify the demands or needs on the part of policymakers for information and political support as triggers for their supply by interest groups (e.g., Berkhout 2013). Interest groups selectively receive access to the policy process in exchange for these goods. We identify an European, executive-oriented tradition and an American, legislative-oriented tradition of exchange-theoretical studies.

First, bureaucratic or executive policymakers face instrumental incentives to realize particular policy outcomes. That is, interest representation is then viewed as an administrative instrument for the efficient execution of electorally mandated policy goals and access is appropriately provided to "interests . . . that are essential to the achievement of a public purpose or those who overt conflict would be socially destructive" (Anderson 1977, 144). Some exchange-theoretical studies, especially those in Europe, note that administrative incentives are likely to lead to a prioritization of "encompassing" interest representation over narrow forms of representation (e.g., Braun 2012; Streeck and Kenworthy 2005) or note intrainstitutional variation in this regard (e.g., Bouwen 2004). As part of neo-corporatist practices, policymakers may offer "representational monopolies" to associations, for instance, by "talking only to organizations that exceed a certain size or qualify as majority representative of their constituency" and may further help privileged associations to eliminate competitors by "tacit or open assistance in recruiting or retaining members, which can take a variety of forms, from moral suasion to compulsory membership" (Streeck and Kenworthy 2005, 450-51). These executive or administrative institutional practices lead to a privileged provision of access, especially in domains with low density.

Second, exchange-theoretical views focusing on U.S. legislative lobbying attend more explicitly to the electoral motivations of politicians. "Informants win access because their offerings . . . suit lawmakers' electoral needs better than those offered by their rivals" (Hansen 1991, 3, 13-14). Some of these information models stay relatively close to the "supermarket" metaphor of economic exchange, where campaign contributions are exchanged for legislative favors (e.g., Austen-Smith 1995; Denzau and Munger 1986). In their less "economic"-inspired contribution model, Hall and Deardorff (2006) note that lobbyists will be selective in their targeting of particular legislators and their choice of intelligence provided. More to the point, lobbyists provide "matching grants," consisting of strategically produced "political intelligence," to support ongoing political initiatives of friendly legislators, and "the more lobbyists lobby their legislative allies, the more those allies will intervene" (Hall and Miller 2008, 994). This 
mechanism suggests that to reduce the size of the "matching grant," lobbyists will target policymakers who are already "subsidized" by other lobbyists, possibly as part of "lobby enterprises" (Ainsworth 1997) and likely to follow cues and "bandwagon" toward particular issues, venues, and actors (e.g., Halpin 2011). In other words, in relatively dense environments, lobbyists are able to, at least partially, free ride on the influence activities of others, and therefore individually require and receive lower levels of access.

Third, to reiterate, policy access, as exchange good, cannot be offered unrestrictedly due to limits in the processing capacity of policymakers (e.g., Jones and Baumgartner 2005). Legislators, bureaucrats, and other political decisionmakers must be selective. This implies, in population-ecological terms, that in domains where the society or the economy guarantees the establishment and survival of large numbers of groups, there is an "oversupply" of potentially important information to policymakers relative to "listening capacity" in the policy process. The oversupply of societal pressures is an important source of control for a policymaker, as he "largely determines for himself what he hears from the public" (Bauer, Pool, and Dexter 1963, 414). The needs of policymakers also depend on their institutional position. That is, policymakers, among other mechanisms, manage to increase their information processing capacity by creating institutions of "parallel information processing" (subdivisions in the legislature and bureaucracy, for example, by creating large numbers of policy fora; Broscheid and Coen 2007). For instance, the relatively large number of members of Congress (largely working in parallel) and the practice of members to offer superficial "generic access" (Sorauf 1992, 72) lead lobbyists to be "virtually awash with access" to the U.S. Congress (Salisbury 1990, 348). In most circumstances, the mobilization capacity of society or the economy (the "area" term of the Energy-Stability-Area or ESA model) exceeds the policy "energy" or "demand" for lobbying in the policy process. In any case, both the "demand" on the part of policymakers and the "supply" of lobbyists determine the number of interest groups in a particular environment (Gray and Lowery 1996).

In other words, when larger numbers of groups are active in a certain policy field, policymakers, whose attention is scarce and largely independent of interest group mobilization, will have to choose with whom to interact. This argument implies that, from the perspective of individual lobbyists, in crowded environments, access is more limited compared with when only a few groups are active. For each organization, it should therefore be more difficult to reach policymakers once there are many more groups active on similar issues. Our main hypothesis is thus as follows:
Hypothesis 1 (H1) "Density hypothesis": Groups active in relatively dense interest communities gain less access than groups active in relatively less crowded interest communities.

Importantly, the population ecology framework provides several explicit hypotheses about the stage of population development and the type of organizations most affected by increased density. In other words, there are certain mediating effects which cause some groups to gain access as competition increases and some groups to lose access. The first mediating effect relates to how interest group populations develop over time (Lowery and Gray 1998; Nownes 2004; Nownes and Lipinski 2005). One of the crucial assumptions in population ecology theory is that interest group populations develop over time in an S-shaped manner, and the density at a certain moment largely depends on prior density (Lowery and Gray 2016). In cross-sectional assessments of the standard population-ecological model (the ESA model), the age or stability of the system is assumed to be the same in the sections studied, or assumed to be empirically inconsequential, as interest group systems only rarely collapse and quickly re-establish themselves. In longitudinal organizational ecological models, it is theorized that in the first stage of system formation, new interest organizations must overcome legitimation issues and several barriers to collective action lead to a slow growth of the density of the system (Hannan and Freeman 1989). In the second stage, the system grows rapidly. In the final stage, an organizational system becomes mature and competitive, and its carrying capacity is realized. New entrants will find it difficult to successfully enter the community, as critical resources such as potential members, policy expertise, and long-term policy relationships are all used by existing groups (Nownes 2015). Please note that this is also consistent with exchange-theoretical models in the sense that older organizations, in earlier, low-dense situations, have had more time to establish relationships with policymakers.

Given the intensely competitive pressures, we should therefore observe that especially in relatively "old," mature systems, density produces relatively limited access. Such organizational dynamics can be observed within particular policy areas, issues, or causes, and also at the level of national interest group systems. Applied to our case, in relatively new democracies, in which the institutionalization of involvement of civil society in policy making has happened more recently, systems should be less mature and without a fully realized carrying capacity. When comparing older democracies such as Belgium and the Netherlands with more recent democracies such as Lithuania and Slovenia, we assume that the transition from communism must be a relevant break for 
the interest group system in a similar way that the Second World War has been for the Belgium and Dutch cases (e.g., van Waarden 1992). We therefore expect countrylevel differences in the relative importance of density of policy fields in relation to the policy access of individual organizations. This leads to the following hypothesis:

Hypothesis 2 (H2) "System saturation hypothesis": The negative effect of interest group density on access is stronger in countries with a mature interest group system than in countries with a relatively young interest system.

The second set of hypotheses derives from niche theory, an integral part of the population ecology perspective (Lowery and Gray 2015, 5). Niche theory suggests that specialization is generally favored in more competitive environments. This competitive benefit adds to a couple of other organizational advantages of greater specificity of representation (Heinz et al. 1993, 376; Wilson 1995, 310-12). In relatively dense fields with relatively high levels of specialization, it is likely that the resource base of relatively broad, encompassing organizations in terms of membership and policy access will come under serious competitive pressure. Over time, lobbying through more specialized associations will become the preferred vehicle for interest representation. Indeed, such partitioning may establish a vicious cycle where resource partitioning weakens the membership income of generalist associations, leading to a new round of establishment of specialized lobbying organizations, which further weakens the generalist associations and starts the cycle anew. This mechanism should explain why some organizations thrive in terms of gaining access in a competitive environment, while others are excluded once competition increases. Building on niche theory, Gray and Lowery (1997a) have suggested specialization in terms of tactics or policy objectives as beneficial for access gained. This is consistent with exchange-theoretical views noted above: those organizations with substantial capacity to produce relevant political intelligence should have a competitive advantage to their peers to exchange information for access to policymakers.

Somewhat similarly, we focus on specialization in the relative strength of the lobby function of interest groups. That is, some groups will specialize in interest representation through lobbying and others will focus on other types of activities, such as creating awareness or providing services to their members. Browne (1990, 499-501) has persuasively argued that the lobby specialists' secure access to the policy process contributes to organization identity, which in turn enhances the organization's prospects for survival. In addition, specialization is encouraged by the distinct organizational demands of members and policymakers (e.g., Ainsworth and Sened 1993; Schmitter and Streeck 1999). For instance, members of a given professional association would like the organization to spend resources on a well-organized annual conference, whereas policymakers would like to provide policy access, but only if the organization is willing to invest in high-quality policy representatives. This creates an internal tension in terms of staff allocation. These distinct demands create incentives for organizations to specialize in either membership services or lobbying. Over time, this leads to lobbying communities consisting of, on one hand, a set of organizations focused on the efficient delivery of services to members and, on the other hand, organizations that we label "lobby specialists" focused on influencing public policy.

According to niche theory, we should expect more specialized lobby groups to increasingly gain access to policymakers compared with groups which do not specialize in lobbying, especially in densely populated interest group communities. Here, the gap in lobbying experience between service-oriented organizations and lobby-oriented organizations is more pronounced. Not only is the gap more significant, but the dynamics from the demand side of lobbying prevent a more equal distribution of access in dense policy domains. The denser a policy field, the more time it takes a policymaker to consider and evaluate each of the organizations in a field that may deliver a certain type of information or support. Using cues such as size and visibility (through specialization) therefore becomes more important in denser communities. As a result, the differences between lobby specialists and those that are not are strengthened in denser policy fields. This leads to the following hypothesis:

Hypothesis 3 (H3) "Lobby specialization hypothesis": The negative effect of interest group density on access is stronger for non-lobby specialists.

Second, competitive pressures may alternatively lead groups to specialize in particular policy objectives, such as specific policy domains or an issue within a policy domain. There are policy strategic incentives and survival incentives to do so. To start, given the common, Balkanized structure of bureaucracies (narrow policy circles each dominated by a few actors), issue specialization increases the likelihood that an organization will be a critical or sole policy interlocutor in domains where policy opponents are avoided and conflict is minimized. Such a position also provides organizations with an "identity" that facilitates membership communication, visibility, and, in the longer term, maintenance of members (Heaney 2004). This form of organizational partitioning in dense communities 
Table I. Descriptive Statistics of Dependent and Independent Variables.

\begin{tabular}{|c|c|c|c|c|c|}
\hline Variable & $n$ & M & $S D$ & Minimum & Maximum \\
\hline DV: Access & $\mathrm{I}, 108(2,660)$ & $\mathrm{I} .53(\mathrm{I} .67)$ & $\mathrm{I} .08(\mathrm{I} . \mathrm{II})$ & 0 & 4 \\
\hline HI: Density & I, I $98(2,855)$ & $8.31(7.52)$ & $4.88(4.46)$ & 0.57 & 21.64 \\
\hline H2: Countries & 4 & NA & NA & I & 4 \\
\hline H3: Lobbying expenses & $264(626)$ & $1.16(1.19)$ & $0.37(0.39)$ & I & 2 \\
\hline H4: Policy specialization & I, I $98(2,855)$ & $2.57(2.01)$ & $0.70(0.86)$ & I & 3 \\
\hline $\mathrm{Cl}$ : Government expenses & $\mathrm{I}, \mathrm{I} 42(2,449)$ & $10.64(10.08)$ & 9.75 ( 11.22$)$ & 0 & 37.5 \\
\hline C2: Resources & $(1,158) 2,725$ & $3.56(3.80)$ & $1.94(1.95)$ & 1 & 8 \\
\hline C3: Professionalization & $(1,197) 2,855$ & $0.13(0.21)$ & $1.68(1.68)$ & -4.52 & 5.21 \\
\hline
\end{tabular}

Statistics of dyads are shown in parentheses. $\mathrm{DV}=$ dependent variable; $\mathrm{H}=$ hypotheses; $\mathrm{C}=$ control variables.

therefore improves the survival prospects of the policy participants.

Gray and Lowery (1997a) explicitly discussed this mechanism and found some indirect effect. Again, we expect groups with a narrow focus to gain more access compared with groups with a broad focus, especially in interest communities. Due to the time constraints of policymakers in dense communities, these groups are forced to take shortcuts to find the right supplier of information. If an organization is the specialist with regard to a specific issue, this is expected to be especially decisive for policymakers. This leads to the second, mediating hypothesis derived from the population ecology literature on how density has a more favorable effect on specialized groups compared with more generalist groups.

Hypothesis 4 (H4) "Issue specialization hypothesis": The negative effect of interest group density on access is stronger for organizations with a low level of issue specialization.

\section{Data and Research Design}

We use data from Dutch, Belgian, Slovenian, and Lithuanian comparative interest group surveys (Beyers et al. 2016; https://www.cigsurvey.eu/). The survey respondents are leaders or representatives of potentially policy-interested national membership associations of individuals or companies. Respondents were asked about organizational characteristics, political activities, and strategies. The survey questionnaire was translated from an English-language European Union (EU)oriented version by each of the research teams and adapted to the respective national contexts. Overall, the response rate to the survey was 38 percent, which is relatively high compared with other online surveys in this field (see Supplemental Appendix 1 for more details on the project).

The concepts introduced earlier were operationalized as follows. The dependent variable in our analysis is access to national policymakers. As access requires some sort of exclusiveness (see Binderkrantz, Pedersen, and Beyers 2017), we rely on the responses to the following question: "On average, how often did policymakers initiate contact with your organization in the last year?" Answers could vary from "never" to "at least once," "at least quarterly," "at least monthly," and "at least weekly." This variable serves our purpose as it assesses actual meetings between policymakers and interest groups where policymakers serve as gatekeepers of this contact. To ensure our results are robust, we also test an alternative measure of access (see Supplemental Appendix 4, also for a discussion of our principal variable; see Table 1).

Our main independent variable is the density of a policy field in which an organization is active (H1). We construct this by aggregating the responses of respondents in each country to the question: "How involved is your organization in the following policy areas?" (See Supplemental Appendix 2 for included policy fields and densities.) For each policy field, we count the number of organizations indicating that they are "very active" in it. We weigh this against the total number of respondents in a country, to measure the relative density of a policy field in a given country (to account for differences in sampling and response rates). ${ }^{1}$

As regards our system saturation hypothesis (H2), we can classify two interest systems in our analyses as mature (the Netherlands and Belgium) and two as relatively young (Slovenia and Lithuania). In the latter two countries, due to later democratization, there are far fewer interest groups and much room for growth of populations, as we assume that the carrying capacity has not yet been fully realized. Rather than adding a dummy for maturity in our main analyses, we run the analyses in each country separately in a second step, to be able to evaluate potential differences within the mature or the relatively young countries.

Finally, the conditional hypotheses (H3 and H4) are measured as follows. First, for the specialization 
hypothesis, we looked at the number of policy fields in which an organization is active. This is similar to the measure of policy breadth used by Halpin and Binderkrantz (2011; also see Halpin and Thomas 2012), although they measured actual policy activity rather than what was stated in a survey. We used a three-point scale in terms of which the organizations active in more than four fields were coded as "1" (not specialized), those active in three or four fields were coded as "2" (somewhat specialized), and those active in one or two fields were coded as " 3 " (very specialized). In contrast to the measure of density, which is constructed per policy field, the policy specialization measure here is specific to each organization. Furthermore, lobby specialization was observed in the relative lobbying expenses compared with the overall budget. Associations spending more than half of their budgets on lobbying were considered lobby specialists. ${ }^{2}$ Unfortunately, this was only measured for Dutch associations.

We controlled for group type, professionalization, and resources. Each of these variables has been put forward by the literature as an important factor, indicating variation in access gained by interest groups. Although we do not know whether and how these variables affect policy access, controlling for them allows us to assess whether density is an important omitted variable in micro-level studies. The group-type variable was coded based on the websites of each of the organizations by the researchers from the respective national teams. The coding scheme included eight categories: business groups, professional associations, labor unions, identity groups, cause groups, leisure groups, associations of institutions, and public authorities (labeled institutional associations); excluded from the analysis was an "any others" category. Second, we controlled for the level of professionalization of an organization by considering the way an organization took decisions, the criteria used when hiring staff, the training of staff, and whether employees were inclined to pursue a career within the organization (see Supplemental Appendix 3 for a detailed description). We also controlled for government activity in a certain policy field, using Eurostat (2015) data on government expenditure by different functions of government as percentages of total expenditure. Finally, financial resources were measured using the 2015 annual budget of each organization. ${ }^{3}$

Because some organizations are active in multiple policy fields, the unit of analysis in our design was the organization-policy field dyad. On average, our respondents indicated that their organization was active in approximately two policy fields (with a standard deviation of 0.86). The procedure described thus approximately doubles the number of observations relative to the number of respondents.
One of the drawbacks of our design is that, even though the units of observations are organization-policy field dyads, we can only observe access at the organization level (rather than measuring access to specific policy fields). In the main table, we nevertheless rely on this measure to throw away as little data as possible. However, we try to account for this measurement problem in three ways in robustness checks presented in Supplemental Appendix 5. First, we run our analyses focusing on organizations active on only one policy field. Second, we aggregate the density of all fields that an organization is active at. Finally, we focus on the fields at which Dutch organizations are most active at. These specifications do not substantially change the results.

Furthermore, the data that we use have a hierarchical structure which we have to account for in our analyses. Implicit in our expectations is that there is heterogeneity between units within policy fields and within countries, which we need to control for in our models. We choose to use simple ordinary least squares (OLS) regressions in which we cluster standard errors on policy field-country combinations. An alternative is to use multilevel models which, as we show in Supplemental Appendix 6, overall lead to the same results. Due to the similarity in the results, and the less strong assumptions this method poses on the data (Steenbergen and Jones 2002), we opt for the OLS regressions with clustered standard errors in the main text. Given the small number of units at the highest level (four countries), we choose to first present models in which we are "naïve" about heterogeneity within countries. In the second step, we run the analyses for each country separately to account for unobserved heterogeneity. In robustness check 6 (Supplemental Appendix 6), we run the analyses with country dummies, which show similar results.

\section{Analysis}

We estimated a number of OLS regression models with clustered standard errors per policy field. This is the base test of our main hypothesis (H1). We present separate models per country to assess the effect of interest group system maturation (H2) and plot predictive margins to visually present the size of the moderating effect of specialization (H3 and H4). In Table 2, the results of the first analysis are presented. In model 1 , we show the bivariate relationship between density and access. The negative and significant coefficient indicates that overall density has an effect on access gained, explaining a mere 2 percent of the variation in access. In model 2 , we add standard explanatory variables explaining access in other studies to the model and find a smaller but significant effect of density. This implies that overall (across the four countries) access is affected by the density of the interest communities in which groups are active. 
Table 2. Linear Regression on Access, Clustered Standard Errors.

\begin{tabular}{|c|c|c|c|c|}
\hline & Model I & Model 2 & Model 3 & Model 4 \\
\hline Relative density & $-0.0379 * * *(0.00644)$ & $-0.0187 * *(0.00616)$ & $-0.043 \mid * *(0.0138)$ & $-0.0191 *(0.00883)$ \\
\hline Resources & & $0.253 * * *(0.0132)$ & $0.316 * * *(0.0199)$ & $0.248 * * *(0.0134)$ \\
\hline Business & & Reference & Reference & Reference \\
\hline Professional & & $-0.307 * * *(0.0663)$ & $-0.299 *(0.129)$ & $-0.297 * * *(0.0676)$ \\
\hline Union & & $-0.146(0.0880)$ & $-0.156(0.210)$ & $-0.191 *(0.0918)$ \\
\hline Identity/religious & & $-0.253 * * *(0.0568)$ & $-0.380 * *(0.104)$ & $-0.28 I * * *(0.058 I)$ \\
\hline Public interest & & $-0.230 *(0.0910)$ & $-0.255^{*}(0.116)$ & $-0.237^{*}(0.0899)$ \\
\hline Leisure/hobby & & $-0.486 * * *(0.0812)$ & $0.0924(0.161)$ & $-0.482 * * *(0.0784)$ \\
\hline Institutional/public & & $0.358 * * *(0.101)$ & $0.268(0.207)$ & $0.363 * * *(0.0949)$ \\
\hline Professionalization & & $0.0329 * *(0.0109)$ & $0.0664 * *(0.0188)$ & $0.0328 * *(0.0110)$ \\
\hline Government expenses & & $0.00460(0.00249)$ & $0.00725 *(0.00323)$ & $0.00457(0.00250)$ \\
\hline Lobby Specialization & & & $0.0896(0.185)$ & \\
\hline Lobby Specialization $\times$ Density & & & $0.04 I 2(0.0239)$ & \\
\hline Sector Specialization I & & & & Reference \\
\hline Sector Specialization 2 & & & & $0.000617(0.109)$ \\
\hline Sector Specialization 3 & & & & $-0.219 *(0.0957)$ \\
\hline Sector Specialization I $\times$ Density & & & & Reference \\
\hline Sector Specialization $2 \times$ Density & & & & $-0.00334(0.0124)$ \\
\hline Sector Specialization $3 \times$ Density & & & & $0.00775(0.0102)$ \\
\hline Constant & $1.955^{* * *}(0.0627)$ & $0.957 * * *(0.0745)$ & $0.908 * * *(0.149)$ & $1.057 * * *(0.102)$ \\
\hline Observations & 2,660 & 2,098 & $54 I$ & 2,098 \\
\hline$R^{2}$ & .023 & .299 & .372 & .303 \\
\hline
\end{tabular}

Standard errors are shown in parentheses.

$*_{p}<.05$. **p $<.01$. ***p $<.001$.

Next, we address our system saturation hypothesis, for which we turn to Table 2. The results confirm our hypothesis on the effects of age of the system. First, for the Netherlands and Belgium, we observe a significant, negative effect of density on access. On the basis of the coefficients, we calculated the size of this effect. In the Belgian case, the average access in respect of its most densely populated field is 0.29 scale points lower (on our five-point scale) than in respect of its least densely populated field. In the Dutch case, this difference is 0.36 points. For Slovenia and Lithuania, we observed no effect of density on access.

These results are mostly in line with our expectations. In Belgium and the Netherlands, with waves of interest group formation in the immediate post-World War II period and the post-materialist wave of the early 1970s, the interest group systems appear to be more mature and saturated, leading to more pronounced system dynamics, such as the relevance of density for access, than in Slovenia and Lithuania, where a substantial proportion of associations is a product of the post-Cold War transition to democracy. This confirms our first hypothesis that density indeed has an effect on access, yet only, as predicted by our second hypothesis, in countries with a mature interest group system. ${ }^{4}$
Next, we looked at the conditional effects. For interactions, we looked at models 3 and 4 in Table 2 and tested the two interaction effects. To begin, in the Dutch-only model 3, we included an interaction between density and lobby specialization. The expectation was that especially groups with a focus on lobbying (i.e., the lobby specialists) would secure access to policymakers once interest communities became denser, at the expense of organizations that specialize in member services, or more generalist organizations focusing on various different tasks (Browne 1990, 499-501; Gray and Lowery 1997a). The results presented in the table are not in line with this expectation. However, when we look at the predictive margins in Figure 1 we see that in very dense policy fields, there is indeed a significant advantage for lobby specialists. We see no effect of lobby specialization in less dense communities. Only in densely populated fields do specialized organizations gain an advantage. The effect is quite considerable: even though there is no difference in sparsely populated communities, in the densest communities lobby specialists score approximately 25 percent higher on the scale measuring access.

This type of lobbying specialization seems to be encouraged by the distinct organizational demands of members and policymakers (Schmitter and Streeck 1999). 


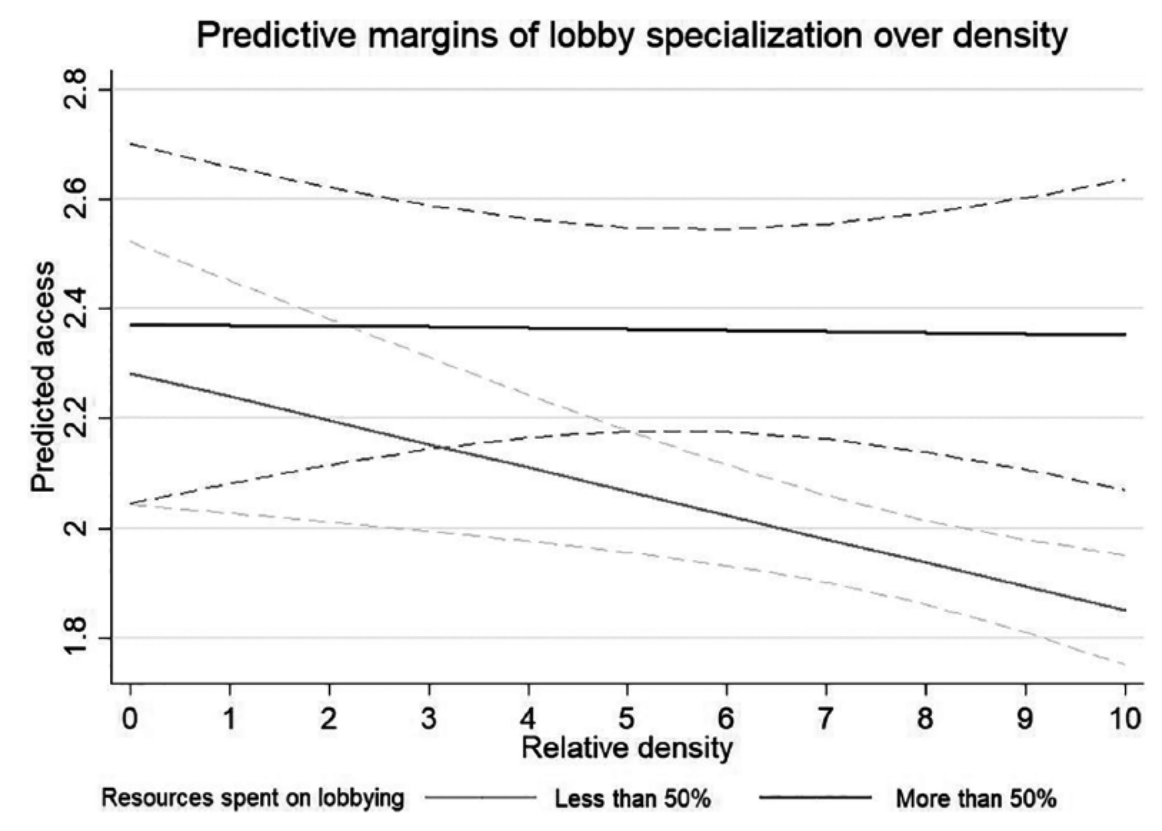

Figure I. Interaction effect of lobby specialization and density on access.

Commonly, the capacity of interest associations to simultaneously bring citizens together for collective purposes (something managed with selective incentives such as membership services), in combination with (or as a "tied sale" or "by-product" in Olsonian terms; Olson 1965) interest representation before government, is associated with high-quality interest intermediation. In other words, should these functions of interest aggregation and articulation not be combined in a single association, as occurs in communities with high proportions of lobby specialists, interest associations no longer effectively function as linking pins or interlocutors between state and society, something that must have implications for our interpretation of the political use of interest representation more generally - or should at least focus our attention for future studies.

Finally, in model 4 (Table 2), we assessed the relation between issue specialization and density. Surprisingly, we found some indication for a negative relation between specialization and access. This may be a result of the fact that we did not measure access to specific policy fields, but to the overall policy process. Groups active in more policy fields may gain more access overall, but less access in each field, relative to specialists. We cannot disentangle this. More importantly, we do not find a changing relationship between the policy breadth of interest groups and the access groups gain to policymakers across varying levels of density. That is, the lobbying success of organizations that specialize in certain policy fields does not increase in dense political arenas. Being an issue specialist does not improve an organization's chances in the political arena once systems become denser. It may be that specialization is largely a competitive advantage in membership (recruitment) activities rather than in relation to public policy. Interest groups may partition their membership resource base in terms of particular issue foci, something that may be largely independent from public policy. For instance, a dense community of cancer patient groups may specialize in particular variants of cancer, and hence partition membership resources, but in direct competition for access to the relevant policy processes. In other words, the advantage of being an issue specialist is related to the long-term survival of groups rather than the short-term access of groups to the policy process. This is certainly something that should be addressed in future research.

As for our control variables, fervent population ecologists assume that the structure of an interest group population largely, if not entirely, determines the strategies groups employ and, ultimately, the outcomes that groups achieve (Lowery and Gray 2015, 7; see also Holyoke 2017). Yet, in the four-country models (see Table 3), the addition of density does not change any of the other effects (namely, group type, resources, or professionalization) in the individual countries (with the exception of two effects of government expenses). This indicates that 


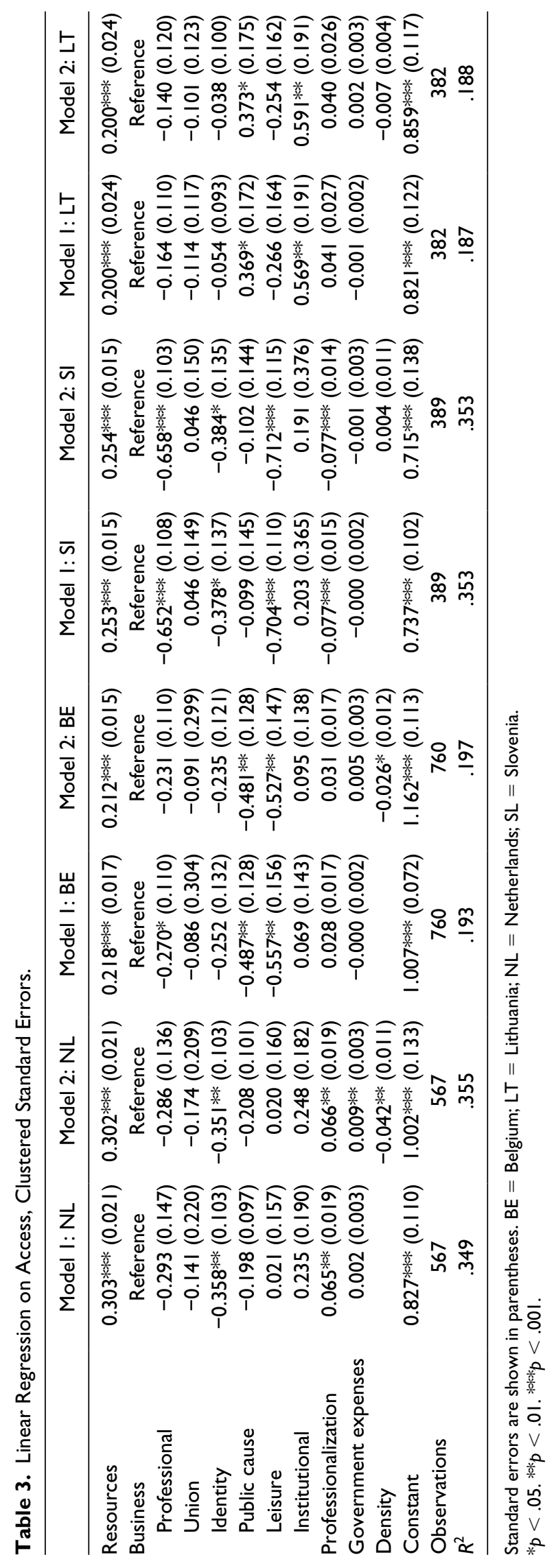


density is an important, but certainly not a sufficient or necessary, condition in explaining access.

\section{Conclusion}

Perhaps the key contribution of population-ecological studies to the literature on interest group politics is the notion that the organizational context is of crucial importance to understand the behavior of individual lobbyists (Leech 2015, 197). Given this notion, it is surprising that one of the most important contextual factors that Gray and Lowery themselves introduced, the effective number of lobbyists present in interest communities, has hardly found its way into the literature on interest group access and influence. Obviously, this has much to do with the problems in collecting data with which to adequately link the macro-organizational context with micro-level lobbying activities (Holyoke 2017; Lowery, Halpin, and Gray 2015, 268). Yet, over the past decade, we have seen a sharp increase in studies mapping interest group communities across various countries and political systems (Berkhout et al. 2018; Halpin and Jordan 2011). These new data sets allow researchers to draw samples from populations and study questions on how macro-level factors affect the behavior of individual groups. In this paper, we relied on data produced by such an extensive data collection project to answer three simple but important questions: does density lead interest groups to gain or lose access to policymakers? And, if it does, does it follow the logic of the most dominant theoretical toolkit in this literature, namely, population ecology theory? Finally, how important is density for access compared with other key explanatory factors for interest group access to the policy process?

On the first question, we found a clear link between the density of the environment within which interest groups operate and the access gained by interest groups to policymakers. This is a substantively important finding, as it indicates that the study of the macro-organizational context matters, not only on its own account but also for studies focusing on the individual behavior of interest groups. In addition and in line with the population ecology approach, in answer to our second question, we found that system maturity matters a great deal. Our country selection allowed for an explicit comparison of young (Slovenia and Lithuania) and old (the Netherlands and Belgium) systems. The maturation of organizational systems is commonly studied using a longitudinal design (e.g., Fisker 2013), but despite our low number of casesnamely, four countries - we believe that there are strong theoretical arguments to assume that, of the various differences between the countries, the age of their interest organizational systems is a plausible explanation for the relatively strong effect of density in the mature systems compared with the young ones.

Second, we found empirical evidence for the population-ecological assumption regarding the relationship between lobbying specialization and density. It was demonstrated that access of specialized groups remains unaffected in denser communities, whereas relatively multi-functional groups have difficulties maintaining their policy function in the face of competitive pressures. This suggests that there is a complex relationship between (internal) organizational maintenance, (external) population-ecological pressures, and the policy-oriented activities of interest groups. Future studies on the strategic choices and influence of interest groups will lead to more specific results if they measure the level of specialization of groups and their organizational context. In contrast to population ecology theory, we did not find any evidence that issue specialization matters more in dense interest communities compared with sparsely populated ones.

Finally, about the third objective, another significant finding is the relative importance of density compared with other explanatory variables. A strict reading of population ecology theory would lead us to assume that the structure of an interest group population largely, if not entirely, determines the strategies groups employ and, ultimately, the outcomes groups achieve (Lowery and Gray 2015, 7). We found no indication that this is true. In no instance did the coefficients or the significance of other important variables, such as resources, group type, or professionalization, change substantially with the addition of density as an explanatory variable to the models. This implies that density is not a critical condition to gain access to policymakers, but rather one of the many factors explaining access by interest groups, each more important under different circumstances. Obviously, much more research is still needed to substantiate this claim, but in this paper, we have not found much evidence that density is a more important factor to understand the processes of access than other explanations often cited in the literature.

These findings speak to the discussion around the complementarity and integrability of macro- and microlevel approaches in interest group studies. The absence of change in effects of variables in traditional models of access after controlling for the omitted variable of "density" suggests that, even though heterogeneity between interest group systems may exist and be relevant for traditional models, as shown by Holyoke (2017), not all central variables in population ecology theory play an equally important role on the level of individual organizations. However, this is not to say that macro-level theories do not contribute to micro-level theories, as suggested by Loomis (2015). As we have demonstrated, 
population-level characteristics (and their interaction with organizational characteristics) can significantly impact organizational opportunities to access policymakers. This speaks in favor of further exploration of the links between the two types of theories.

The results provide many avenues for future research, and more research is needed to further test the relationship between population-level characteristics and organization-level factors. To further test whether differences in population density also affect political outcomes, as it affects the distribution of access, research is needed on the relationship between density and the influence of interest organizations. Furthermore, there is potential for studies on other population characteristics, such as the diversity of policy communities rather than their density. Research assessing the relationship between the diversity of populations and key strategic factors, such as access, other (membership) mobilization activities, and influence, would make an important contribution to the field of interest group politics. Last, the micro-level needs of lobbyists and policymakers, and the macrolevel density, are clearly not constant over time. Population-ecological studies and exchange-theoretical views rely on important assumptions about processes of change such as specialization within particular niches, the long-term institutionalization of relationships, and strategic organizational adaptation of lobbyists. Future studies may assess the implication of these processes on the access of lobbyists to policymakers, therewith also contributing to a better understanding of the responsiveness of interest group politics to changing circumstances.

\section{Acknowledgments}

We are thankful for the insightful and constructive feedback received from three anonymous reviewers and the participants of the workshop "Comparative research on interest group politics in Europe" in Ljubljana in June 2017 and the workshop "Lobbying in context" at the annual meeting of the Dutch Political Science Association (NKWP) in Leiden in May 2018. We are also grateful to Jan Beyers for initiating and organizing the "Comparative Interest Group Survey."

\section{Declaration of Conflicting Interests}

The author(s) declared no potential conflicts of interest with respect to the research, authorship, and/or publication of this article.

\section{Funding}

The author(s) disclosed receipt of the following financial support for the research, authorship, and/or publication of this article: We thank the European Research Council (ERC-2013-CoG 616702-iBias, principal investigator Jan Beyers) for its financial contribution. We also benefited from the financial support of the NWO (Hanegraaff VENI Grant: 451-16-016 and Berkhout VENI Grant: 451-12-017).

\section{Notes}

1. Alternative operationalizations, most notably the raw numbers, do not lead to different outcomes.

2. For this, we rely on answers to the following question: "Organizations like yours have to spend resources on many things. Can you tell us what percentage of your total resources is spent on influencing public policies?" This question is measured using six categories. For the analysis, these were recoded into two categories: less than 50 percent and more than 50 percent. This question was only included in the Dutch survey and therefore only empirically assessed in a separate Dutch-only model.

3. Respondents were provided with eight answer categories to the following question: "What was the annual operating budget of your organization in 2015 in euros?"

4. Besides system age, we also tested the effects of organization age as a (control) variable, as new entrants likely find entrance difficult, as critical resources such as potential members, policy expertise, and long-term policy relationships are all used by existing groups (Nownes 2015). Even though we found consistent positive effects of organization age on access across models, it did not alter the effect of density (nor of other variables in the model).

\section{Supplemental Material}

Supplemental materials and replication materials for this article are available with the manuscript on the Political Research Quarterly (PRQ) website.

\section{ORCID iD}

Joost Berkhout (iD) https://orcid.org/0000-0003-0527-8960

\section{References}

Ainsworth, Scott H. 1997. "The Role of Legislators in the Determination of Interest Group Influence." Legislative Studies Quarterly 22:517-33.

Ainsworth, Scott H., and Itai Sened. 1993. "The Role of Lobbyists: Entrepreneurs with Two Audiences." American Journal of Political Science 37:834-66.

Anderson, Charles W. 1977. "Political Design and the Representation of Interests." Comparative Political Studies 10 (1): 127-52.

Austen-Smith, David. 1995. "Campaign Contributions and Access." American Political Science Review 89 (3): 566-81.

Bauer, Raymond Augustine, Ithiel de Sola Pool, and Lewis Anthony Dexter. 1963. American Business and Public Policy: The Politics of Foreign Trade. New York: Atherton Press.

Baumgartner, Frank R., and Beth L. Leech. 1998. Basic Interests: The Importance of Groups in Politics and in Political Science. Princeton: Princeton University Press.

Baumgartner, Frank R., and Kelsey Shoub. 2015. "Population Dynamics and Representation." In The Organization 
Ecology of Interest Communities: Assessment and Agenda, edited by David Lowery, Darren Halpin, and Virginia Gray, 203-24. London: Palgrave Macmillan.

Berkhout, Joost. 2013. "Why Interest Organizations Do What They Do: Assessing the Explanatory Potential of 'Exchange' Approaches." Interest Groups \& Advocacy 2 (2): 227-50.

Berkhout, Joost, Jan Beyers, Caelesta Braun, Marcel Hanegraaff, and David Lowery. 2018. "Making Inference across Mobilisation Influence Research: Comparing TopDown Bottom-Up Mapping of Interest Systems.” Political Studies 66 (1): 43-62.

Beyers, Jan, Patrick Bernhagen, Caelesta Braun, Danica FinkHafner, Frederik Heylen, William Maloney, Daniel Naurin, and Dominic Pakull. 2016. Comparative Interest Group Survey Questionnaire. Antwerp: University of Antwerp.

Binderkrantz, Anne S., Helene H. Pedersen, and Jan Beyers. 2017. "What Is Access? A Discussion of the Definition and Measurement of Interest Group Access." European Political Science 16:306-21.

Bouwen, Pieter. 2004. "Exchanging Access Goods for Access: A Comparative Study of Business Lobbying in the European Union Institutions." European Journal of Political Research 43 (3): 337-69.

Braun, Caelesta. 2012. "The Captive or the Broker? Explaining Public Agency-Interest Group Interactions." Governance 25 (2): 291-314.

Broscheid, Andreas, and David Coen. 2007. "Lobbying Activity and Fora Creation in the EU: Empirically Exploring the Nature of the Policy Good." Journal of European Public Policy 14 (3): 346-65.

Browne, William P. 1990. "Organized Interests and Their Issue Niches: A Search for Pluralism in a Policy Domain." The Journal of Politics 52 (2): 477-509.

Denzau, Arthur T., and Michael C. Munger. 1986. "Legislators and interest groups: How unorganized interests get represented." American Political Science Review 80 (1): 89-106.

Eurostat. 2015. "General Government Expenditure by Function (COFOG)." https://ec.europa.eu/eurostat/statistics-explained/index.php/Government_expenditure_by_ function_\%E2\%80\%93_COFOG.

Fisker, Helene Marie. 2013. "Density Dependence in Corporative Systems: Development of the Population of Danish Patient Groups (1901-2011)." Interest Groups \& Advocacy 2 (2): 119-38.

Gray, Virginia, and David Lowery. 1996. "A Niche Theory of Interest Representation.” The Journal of Politics 58 (1): 91-111.

Gray, Virginia, and David Lowery. 1997a. "Life in a Niche: Mortality Anxiety among Organized Interests in the American States." Political Research Quarterly 50 (1): 25-47.

Gray, Virginia, and David Lowery. 1997b. "Reconceptualizing PAC Formation: It's Not a Collective Action Problem, and It May Be an Arms Race." American Politics Quarterly 25 (3): 319-46.

Hall, Richard L., and Alan V. Deardorff. 2006. "Lobbying as legislative subsidy." American Political Science Review 100 (1): 69-84.
Hall, Richard L., and Kristina C. Miler. 2008. "What Happens after the Alarm? Interest Group Subsidies to Legislative Overseers." The Journal of Politics 70 (4): 990-1005.

Halpin, Darren. 2011. "Explaining Policy Bandwagons: Organized Interest Mobilization and Cascades of Attention." Governance 24 (2): 205-30.

Halpin, Darren, and Anne S. Binderkrantz. 2011. "Explaining Breadth of Policy Engagement: Patterns of Interest Group Mobilization in Public Policy." Journal of European Public Policy 18 (2): 201-19.

Halpin, Darren, and Grant Jordan. 2009. "Interpreting Environments: Interest Group Response to Population Ecology Pressures." British Journal of Political Science 39 (2): 243-65.

Halpin, Darren, and Grant Jordan. 2011. The Scale of Interest Organization in Democratic Politics: Data and Research Methods. New York: Springer.

Halpin, Darren, and Herschel F. Thomas III. 2012. "Evaluating the Breadth of Policy Engagement by Organized Interests." Public Administration 90 (3): 582-99.

Hannan, Michael T., and John Freeman. 1989. Organizational Ecology. Cambridge: Harvard University Press.

Hansen, John Mark. 1991. Gaining access: Congress and the farm lobby, 1919-1981. Chicago: University of Chicago Press.

Heaney, Michael T. 2004. "Outside the Issue Niche: The Multidimensionality of Interest Group Identity." American Politics Research 32 (6): 611-51.

Heinz, John P., Edward O. Laumann, Robert L. Nelson, and Robert H. Salisbury. 1993. The Hollow Core: Private Interests in National Policy Making. Cambridge: Harvard University Press.

Hojnacki, Marie, David C. Kimball, Frank R. Baumgartner, Jeffrey M. Berry, and Beth L. Leech. 2012. "Studying Organizational Advocacy and Influence: Reexamining Interest Group Research." Annual Review of Political Science 15:379-99.

Holyoke, Thomas T. 2015. "Challenges of Integrating Levels of Analysis in Interest Group Research." In The Organization Ecology of Interest Communities: Assessment and Agenda, edited by David Lowery, Darren Halpin, and Virginia Gray, 79-97. London: Palgrave Macmillan.

Holyoke, Thomas T. 2017. "Interest Group and Lobbying Research in a Higher Level Context: Two Tests of Integrating Multiple Levels of Analysis." American Politics Research 45 (5): 887-902.

Jones, Bryan D., and Frank R. Baumgartner. 2005. The Politics of Attention: How Government Prioritizes Problems. Chicago: University of Chicago Press.

Leech, Beth L. 2015. "Interest Community Influence: A Neopluralist Perspective." In The Organization Ecology of Interest Communities: Assessment and Agenda, edited by David Lowery, Darren Halpin, and Virginia Gray, 183201. London: Palgrave Macmillan.

Loomis, Burdett. 2015. "Beyond Metaphor: Populations and Groups, Interests, and Lobbyists." In The Organization Ecology of Interest Communities: Assessment and Agenda, edited by David Lowery, Darren Halpin, and Virginia 
Gray, 249-61 (Interest Groups, Advocacy and Democracy Series). London: Palgrave Macmillan.

Lowery, David. 2015. "Mancur Olson, the Logic of Collective Action: Public Goods and the Theory of Groups." In The Oxford Handbook of Classics in Public Policy and Administration, edited by Martin Lodge, Edward C. Page, and Steven J. Balla, 205-20. Oxford: Oxford University Press.

Lowery, David, and Virginia Gray. 1995. "The Population Ecology of Gucci Gulch, or the Natural Regulation of Interest Group Numbers in the American States." American Journal of Political Science 39:1-29.

Lowery, David, and Virginia Gray. 1998. "The Dominance of Institutions in Interest Representation: A Test of Seven Explanations." American Journal of Political Science 42 (1): 231.

Lowery, David, and Virginia Gray. 2004. "A Neopluralist Perspective on Research on Organized Interests." Political Research Quarterly 57 (1): 164-75.

Lowery, David, and Virginia Gray. 2015. “An Introduction to the Population Ecology Approach.” In The Organization Ecology of Interest Communities: Assessment and Agenda, edited by David Lowery, Darren Halpin, and Virginia Gray, 1-15. London: Palgrave Macmillan.

Lowery, David, and Virginia Gray. 2016. "On the Political Origins of Bias in the Heavenly Chorus." Interest Groups \& Advocacy 5 (1): 25-56.

Lowery, David, Virginia Gray, Justin Kirkland, and Jeffrey J. Harden. 2012. "Generalist Interest Organizations and Interest System Density: A Test of the Competitive Exclusion Hypothesis." Social Science Quarterly 93 (1): 21-41.

Lowery, David, Darren Halpin, and Virginia Gray. 2015. "The Future of Organization Ecology in Interest Representation." In The Organization Ecology of Interest Communities: Assessment and Agenda, edited by David Lowery, Darren Halpin, and Virginia Gray, 263-74. London: Palgrave Macmillan.

Nownes, Anthony J. 2004. “The Population Ecology of Interest Group Formation: Mobilizing for Gay and Lesbian Rights in the United States, 1950-98." British Journal of Political Science 34 (1): 49-67.

Nownes, Anthony J. 2015. "Organizational Demography Research in the United States." In The Organization Ecology of Interest Communities: Assessment and Agenda, edited by David Lowery, Darren Halpin, and Virginia Gray, 17-36. London: Palgrave Macmillan.

Nownes, Anthony J., and Daniel Lipinski. 2005. "The Population Ecology of Interest Group Death: Gay and Lesbian Rights Interest Groups in the United States, 1945-98.” British Journal of Political Science 35 (2): 303-19.

Olson, Mancur. 1965. The Logic of Collective Action. Cambridge: Harvard University Press.

Olson, Mancur. 1982. The Rise and Decline of Nations: Economic Growth, Stagflation, and Social Rigidities. New Haven: Yale University Press.

Salisbury, Robert H. 1990. The Paradox of Interest Groups in Washington-More Groups, Less Clout. New York: Springer.

Schattschneider, Elmer E. 1960. The Semi-sovereign People: A Realist's View of American Democracy. New York: Holt, Rinehart \& Winston.

Schmitter, Philippe C., and Wolfgang Streeck. 1999. "The Organization of Business Interests: Studying the Associative Action of Business in Advanced Industrial Societies." MPIfG Discussion Paper 1999/01. https://cadmus.eui.eu/handle/1814/21980.

Sorauf, Frank J. 1992. Inside Campaign Finance: Myths and Realities. New York: Yale University Press.

Steenbergen, Marco R., and Bradford S. Jones. 2002. "Modeling Multilevel Data Structures." American Journal of Political Science 46:218-37.

Truman, David. 1951. The Governmental Process. New York: Knopf.

Van Waarden, Frans. 1992. "Emergence and Development of Business Interest Associations. An Example from the Netherlands." Organization Studies 13 (4): 521-61.

Wilson, James Q. 1995. Political Organizations. Princeton: Princeton University Press. 